\title{
Sistem Pemilihan Smartphone Berdasarkan Spesifikasinya Pada Mahasiswa Sistem Informasi Universitas Tanjungpura Menggunakan Metode Simple Additive Weighting (SAW)
}

\author{
Renny Puspita Sari, Bayu Saputra \\ Fakultas Matematika dan Ilmu Pengetahuan Alam, Sistem Informasi, Universitas Tanjung Pura, Pontianak, Indonesia \\ Email: rennysari.untan@gmail.com, bayubek@student.untan .ac.id \\ Submitted: 11/05/2021; Accepted: 26/05/2021; Published: 30/05/2021
}

\begin{abstract}
Abstrak-Teknologi saat ini sering digunakan oleh semua kalangan salah satunya mahasiswa pada jurusan Sistem Informasi yang berada di Universitas Tanjungpura. Salah satu teknologi yang digunakan adalah Smartphone yang menjadi alat bagi mahasiswa untuk saling berkomunikasi bahkan dikala pandemi saat ini Smartphone digunakan untuk belajar juga dan tiap tiap Smartphone memiliki spesifikasinya tersendiri yang membuatnya unggul dari pada Smartphone lainnya tentu saja dengan banyaknya Smartphone yang beredaran di pasar maka pasti akan bingung dalam melakukan pemilihannya, dengan demikian maka sispem pendukung keputusan untuk memilih Smartphone berdasarkan spesifikasinya dibuat untuk tujuan membantu dalam pemilihan Smartphone tersebut. Metode Simple Additive Weighting (SAW) yang digunakan untuk menyelesaikan system pendukung keputusan Pemilihan Smartphone Saat Pandemi Pada Mahasiswa Sistem Informasi Universitas Tanjungpura yang menggunakan penjumlahan terbobot pada setiap rating kinerja pada setiap alternatif. Pada Penelitian ini hasil dari perhitungan yang didapat dari survey yaitu Samsung S21 5G dengan nilai 73.75, Iphone 11 64GB dengan nilai 48.75, Vivo Y17 dengan nilai 81.25, Asus ROG Phone 5 dengan nilai 80, Oppo A92 dan dengan nilai 96.
\end{abstract}

Kata Kunci: Informasi; SAW; Smartphone; Pandemi; SPK

Abstract-Current technology is often used by all groups, one of which is students in the Information Systems department at Tanjungpura University. One of the technologies used is a Smartphone which is a tool for students to communicate with each other even during the current pandemic, Smartphones are used for learning as well and each Smartphone has its own specifications that make it superior to other Smartphones, of course with the number of Smartphones circulating in the market. will be confused in making the selection, thus the decision support system to choose a Smartphone based on the specifications is made for the purpose of assisting in the selection of the Smartphone. The Simple Additive Weighting (SAW) method is used to complete the decision support system for Smartphone Selection During the Pandemic for the Tanjungpura University Student Information System which uses weighted summation for each performance rating for each alternative. In this study, the results of the calculations obtained from the survey are Samsung S21 5G with a value of 73.75, Iphone $1164 \mathrm{~GB}$ with a value of 48.75 , Vivo Y17 with a value of 81.25, Asus ROG Phone 5 with a value of 80, Oppo A92 and with a value. 96.

Keywords: Information; SAW; Smartphone; Pandemic; DSS

\section{PENDAHULUAN}

Di era globalisasi ini teknologi menjadi salah satu kebutuhan pokok yang dimiliki oleh setiap manusia untuk memenuhi segala kebutuhan sehari hari mereka. Serta perkembangan teknologi yang sangat dominan saat ini membuat masyarakat dipaksa untuk ikut perkembangannya salah satu contoh teknologi yang berkembang saat ini yaitu Smartphone (Handphone Pintar).

Menurut David Wood, telepon pintar dapat dibedakan dengan telepon genggam biasa dengan dua cara fundamental, yaitu bagaimana mereka dibuat dan apa yang mereka bisa lakukan. Jika telepon dapat melakukan lebih dari sekedar membuat panggilan telepon yang sederhana, maka dapat dikatakan bahwa telepon tersebut adalah Smartphone[1]. Setelah dilakukan survei ulang, eMarketer mempublikasikan kembali jumlah pengguna smartphone dari tahun 2015 terdapat 65,2 juta pengguna smartphone, tahun 2016 terdapat 65,2 juta pengguna, tahun 2017 terdapat 74,9 juta pengguna smartphone, dan tahun 2018 terdapat 83,5 juta pengguna smartphone di Indonesia hingga diperkirakan tahun 2019 terdapat 92 juta pengguna smartphone [2]. Smartphone merupakan suatu teknologi yang perkembangannya sangat pesat, berawal dari teknologi yang bernama Handphone yang hanya memiliki sedikit fitur misalnya menelpon seseorang dan mengirim pesan. Berawal dari teknologi Handphone inilah manusia mengembangkannya menjadi Smartphone yang memiliki banyak fitur yang tidak dimiliki oleh Handphone pada masa lampau. Karena hal itulah banyak masyarakat sudah beralih menggunakan Smartphone yang banyak memiliki kegunaan dalam memenuhi keperluan sehari hari mereka mulai dari berkomunikasi antar satu sama lain, bermain Game, menghibur diri, belajar hingga berbisnis secara Online. Sehingga banyak merk Smartphone mengeluarkan tipe-tipe Smartphone yang bervariasi dengan spesifikasi yang berbeda pula. Spesifikasi sebuah Smartphone sangat mempengaruhi kinerja dari Smartphone tersebut dan fungsi utama dari Smartphone tersebut, untuk itulah pemilihan Smartphone yang tepat dapat mempengaruhi kegiatan sehari hari yang dilakukan oleh pengguna Smartphone tersebut.

Pada setiap Smartphone terdapat beberapa spesifikasi khusus yang dimiliki setiap Smartphone yang membedakan Smartphone tersebut dengan Smartphone yang lain. Spesifikasi-spesifikasi tersebut antara lain yaitu Chipshet yang digunakan suatu Smartphone, RAM/ROM yang dimiliki suatu Smartphone, kualitas kamera yang dimiliki suatu Smartphone, ukuran layar dari suatu Smartphone, kualitas sinyal yang dimiliki suatu Smartphone, dan harga suatu Smartphone. Pada setiap spesifikasi terdapat berbagai keunggulan tersendiri dan sehingga dalam 
pemilihannya mahasiswa memiliki penilaiannya sendiri namun terkadang hal tersebut tidak sesuai dengan keperluan yang mereka perlukan serta melampaui kemampuan yang mereka miliki sehingga sering terjadi kesalahan dalam memilih smarphone tersebut.

Karena hal tersebutlah penentuan Smartphone yang akan digunakan untuk keperluan sehari-hari memang terlihat sepele di namun bagi beberapa kalangan pemilihan Smartphone yang tepat merupakan hal krusial terutama pada mahasiswa untuk memenuhi keperluan sehari hari mereka berdasarkan spesifikasi dari Smartphone yang ada sehingga tidak ada kesalahan atau penyesalan dalam memilih Smartphone yang akan digunakan. Serta tergantung dari spesifikasi Smartphone yang ada mahasiswa dapat melakukan kegiatan yang diperlukan mereka melalui Smartphone yang mereka miliki mulai dari keperluan belajar misalnya pertemuan kuliah serta mengerjakan tugas, menghibur diri dengan cara menonton, bermain Game, dan kegiatan lainnya dikala senggang bahkan melalui Smartphone mahasiswa dapat bekerja dan memulai bisnis mereka sendiri secara Online.

Dengan menggunakan metode perhitungan Simple Additive Weighting (SAW) perhitungan dilakukan dengan cara menyeleksi alternative-alternatve yang ada dengan cara menghitung kriteria kriteria yang dimiliki oleh masing masing alternative dan kemudian akan didapatkan hasil dari perhitungan tersebut yang akan digunakan oleh user untuk menentukan pilihan yang telah tersedia. Hal ini dapat membantu pengguna yang masih kebingungan dalam menentukan pemilihan suatu keputusan terutama dalam hal-hal yang krusial[3], [4]. Namun perhitungan yang telah dilakukan tidak serta-merta harus selalu diikuti oleh user (pengambil keputusan), karena hal yang telah dihitung sebelumnya hanya menjadi tolak ukur bagi si pengambil keputusan yang tidak wajib diambil dikarenakan jika si pengambil keputusan memiliki hak dalam memilih keputusan tersebut. Dalam kasus ini kriteria yang diambil yaitu (1) Jenis Chipset yang digunakan, (2) Ukuran RAM/ROM (penyimpanan yang terdapat pada Smartphone), (3) Ukuran layar Smartphone, (3) Harga Smartphone.

Berdasarkan kriteria di atas yang menjadi prioritas dari kriteria tersebut adalah harga Smartphone adalah patokan dalam hal memilih suatu Smartphone bagi beberapa kalangan dari menengah ke bawah mengengah ke atas terutama bagi mahasiswa yang belum memiliki keuangan yang terbatas Harga adalah jumlah uang yangditagihkan untuk suatu produk atau jasa, jumlah nilai yang dipertukarkan konsumen untuk manfaat memiliki atau menggunakan produk atau jasa [5]. Sementara Jenis Chipset yang digunakan dikarenakan jenis suatu Chipset dari suatu Smartphone mempengaruhi kinerja/peforma Smartphone tersebut sehingga dapat menunjang fitur fitur yang terdapat di Smartphone tersebut, untuk ukuran RAM/ROM adalah ruang penyimpanan yang dapat menyimpan beberapa aplikasi, sedangkan untuk ukuran layar Smartphone digunakan untuk tampilan Smartphone agar lebih jelas, dan harga Smartphone adalah patokan dalam hal memilih suatu Smartphone bagi beberapa kalangan dari menengah ke bawah, mengengah ke atas terutama bagi mahasiswa yang belum memiliki keuangan yang terbatas.

Rifa'i (2016) dalam penelitiannya berjudul implementasi sistem pendukung keputusan pemilihan gadget terbaik dengan metode Weighted Product. Kriteria yang digunakan berupa, merk, spesifikasi dan harga, merk[6]. Berdasarkan paparan data Consumer Lab Ericsson, selain sebagai alat komunikasi, smartphone memiliki fungsi lain. Dari riset di tahun 2009, terdapat lima fungsi smartphone yang ada di masyarakat. Smartphone yang dulunya hanya berfungsi sebagai alat komunikasi, kini pun telah berubah. Berikut persentase 5 fungsi smartphone bagi masyarakat Indonesia: (1) Sebagai alat Komunikasi agar tetap terhubung dengan teman ataupun keluarga $=65 \%$, (2) Sebagai simbol kelas masyakarat $=44 \%$, (3) Sebagai penunjang bisnis $=49 \%$, (3) Sebagai pengubah batas sosial masyarakat $=36 \%$, (4) Sebagai alat penghilang stress $=36 \%[7]$.

Sistem yang diciptakan ini semoga dapat menjadi tolak ukur bagi mahasiswa agar dapat memilih Smartphone yang tidak hanya sesuai dengan kemampuan namun juga sesuai dengan kebutuhan agar tidak terjadi lagi kesalahan dalam pemilihan Smartphone, karena Smartphone saat ini adalah kebutuhan krusial bagi seluruh kalangan masyarakat. Serta dapat memudahkan keperluan mahasiswa yang terkait dengan penggunaan Smartphone baik untuk keperluan belajar maupun menghibur diri apalagi dimasa pandemic seperti saat ini.

\section{METODE PENELITIAN}

\subsection{Sistem Pendukung Keputusan}

Situmorang (2016) dalam penelitiannya berjudul sistem pendukung keputusan pemilihan calon peserta olimpiade sains tingkat Kabupaten Langkat pada Madrasah Aliyah Negeri (MAN) 2 Tanjung Pura dengan menggunakan metode Simple Additive Weighting[6]. Sistem Pendukung Keputusan atau Decision Support Sistems (DSS) didefinisikan oleh Michael S.Scott Morton sebagai sistem berbasis komputer interaktif, yang membantu para pengambil keputusan untuk menggunakan data dan berbagai model untuk memecahkan masalah-masalah tidak terstruktur[8]. Sistem dapat diartikan adalah suatu kumpulan dari elemen-elemen yang disatukan sehingga terbentuklah suatu elemen baru yang dapat membantu manusia dalam memenuhi suatu tujuannya[9]. Pada era modern saat ini keberadaan sistem sudah tidak bisa dihindari lagi perkembangannya mulai dari sistem offline sampai sistem online sekarang sudah banyak beredar di kalangan masyarakat, terutama pada sistem online.

\subsection{Tahapan Penelitian}

Untuk menjalankan penelitian ini terdapat beberapa tahap yaitu: 
1. Pengumpulan data

Pada tahap ini dilakukan pengumpulan data untuk menunjang kebutuhan dalam melakukan penelitian ini sehingga penelitian yang dilakukan tidak terdapat kesalahan. Pengumpulan data yang dilakukan menggunakan media Google Form untuk menentukan kriteria yang akan digunakan serta sub kriteria yang akan digunakan.

2. Analisa data

Analisa data dilakukan secara bertahap mulai dari perhitungan kriteria paling banyak terpilih hingga masuk ke sub kriteria masing masing agar tidak terjadi kesalahan dalam perhitungan pengujian serta sistem yang dirancang dapat dibangun sesuai keinginan.

3. Perancangan Sistem Pendukung Keputusan

Pada tahap ini dilakukan perancangan sistem mulai dari alur dari sistem (FlowChart) hingga tampilan sistem

4. Pengujian metode penelitian menggunakan Simple Additive Weigthing

Tahap ini dilakukan perhitungan pada kriteria yang telah didapat sebelumnya dan altetive yang tersedia.

5. Laporan Hasil penelitian

Membuat laporan hasil penelitian.

\subsection{Metode Simple Additive Weighting (SAW)}

Metode Simple Additive Weighting atau sering juga disebut dengan penjumlahan terbobot. Untuk mencari penjumlahan terbobot dari rating kinerja pada setiap alternative dari semua atributnya (kriterianya). Dengan rumus sebagai berikut:

a. Rumus perhitungan matriks Simple Additive Weighting (SAW)

$$
r_{i j}=\left\{\begin{array}{l}
\frac{X_{i j}}{\operatorname{Max} X_{i j}} \text { Jika } j \text { adalah atribut keuntungan (benefit) } \\
\frac{\text { Min } X_{i j}}{X_{i j}} \text { Jika } j \text { adalah atribut biaya (cost) }
\end{array}\right.
$$

Dimana $r_{i j}$ adalah matrik ternormalisasi dari alternative $A_{i}$ pada atribut $C_{i j}$ yang mana nilai preferensi untuk setiap alternative diberikan sebagai berikut:

Dimana:

$r_{i j} \quad=$ rating kinerja ternormalisasi

$\operatorname{Max} X_{i j}=$ nilai maksimum dari setiap baris dan kolom

$\operatorname{Min} X_{i j}=$ nilai minimum dari setiap baris dan kolom

$X_{i j} \quad=$ baris dan kolom dari matriks

b. Rumus Perangkingan Simple Additive Weighting (SAW)

$$
V_{i}=\sum_{j=1}^{n} W_{j} r_{i j}
$$

Nilai $V_{i}$ mempengaruhi terpilihnya suatu alternative jika nila $V_{i}$ semakin besar maka alternative tersebut akan terpilih.

Dimana:

$V_{i}=$ Nilai akhir dari suatu alternative

$W_{j}=$ bobot yang telah ditentikan

$r_{i j}=$ matriks ternormalisasi

Ada beberapa langkah dalam penyelesaian metode SAW, sebagai berikut :

a. Menentukan kriteria-kriteria yang akan dijadikan acuan dalam pengambilan keputusan, yaitu $\mathrm{Ci}$.

b. Menentukan rating kecocokan setiap alternatif pada setiap kriteria.

c. Membuat matriks keputusan berdasarkan kriteria (Ci), kemudian melakukan normalisasi matriks berdasarkan persamaan yang disesuaikan dengan jenis atribut seperti (atribut keuntungan ataupun atribut biaya) sehingga diperoleh matriks ternormalisasi $\mathrm{R}$.

d. Hasil akhir diperoleh dari proses perankingan yaitu penjumlahan dari perkalian matriks ternormalisasi $\mathrm{R}$ dengan vektor bobot sehingga diperoleh nilai terbesar yang dipilih sebagai alternatif terbaik (Ai) sebagai solusi[10]-[12].

\section{HASIL DAN PEMBAHASAN}

\subsection{Penentuan Kriteria}

Pada sistem pendukung keputusan kriteria sangat penting untuk melakukan proses perhitungan menggunakan metode yang telah dipilih. Menurut (Asnawati dan Kanedi, 2012) "Kriteria penilaian dapat ditentukan sendiri sesuai dengan kebutuhan perusahaan"[13]. Disini kriteria akan membantu proses perhitungan menggunakan metode Simple Additive Weighting (SAW) dan pada Smartphone terdapat banyak spesifikasinya yang dimana 
spesifikasi pada Smartphone akan digunakan sebagai kriteria pemilihan Smartphone tersebut. Dan untuk mengetahui kriteria yang diinginkan makan dilakukanlah survey pada beberapa mahasiswa disini yang menjadi target survey yaitu mahasiswa Sistem Informasi Universitas Tanjungpura dilakukan mulai dari kriteria yang mereka inginkan, hingga sub kriterianya antara lain:

a. Jenis Chipset Yang Digunakan

Disini terdapat banyak jenis Chipset sehingga dilakukan survey yaitu jenis chipset apa yang terbaik bagi mahasiswa tersebut dan didapatlah hasilnya atau sub kriterianya yaitu:

1. Qualcomm Snapdragon

2. Exynos

3. Mediatek

4. Apple

b. Ukuran dari RAM/ROM

Ukuran RAM/ROM dari suatu Smartphone sangat berpengaruh pada kinerja dan penyimpanan yang dimiliki oleh Smartphone tersebut sehingga hal ini termasuk salah satu spesifikasi yang banyak dicari oleh masyarakat dan dilakukan survey yaitu berapa ukuran RAM/ROM yang terbaik bagi mahasiswa tersebut dan didapatlah hasilnya atau sub kriterianya yaitu:
1. $2 / 16 \mathrm{~GB}$
2. $4 / 64 \mathrm{~GB}$
3. $6 / 128 \mathrm{~GB}$
4. $8 / 128 \mathrm{~GB}$

c. Ukuran Layar Smartphone

Layar suatu Smartphone sangat berpengaruh pada tampilan dan kenyamanan saat memainkan Smartphone tersebut dan kebanyakan pemilihan suatu Smartphone tergantung dari layarnya yang mendukung segala kegiatan yang dilakukan ileh penggunanya sehingga dilakukan survey yaitu berapa ukuran layar Smartphone yang pas bagi mahasiswa tersebut dan didapatlah hasilnya atau sub kriterianya yaitu:
1. $4,4 "$
2. $5,0 "$
3. 5,5
4. $5,7^{\prime \prime}$
5. $6,0 "$

\section{d. Harga Smartphone}

Tingkat kemampuan ekonomi setiap orang berbeda beda hal inilah yang berpengaruh kepada pemilihan Smartphone yaitu harga suatu Smartphone yang sangat bervariasi ada yang murah hingga yang paling mahal dan membuat banyak mahasiswa berfikir untuk membeli suatu Smartphone sehingga dilakukan survey yaitu berapa harga suatu Smartphone yang pas bagi mahasiswa tersebut dan didapatlah hasilnya atau sub kriterianya yaitu:

1. < Rp. 4.000.000,00;

2. Rp. 4.000.000,00; - Rp. 6.000.000,00;

3. >Rp. 6.000.000,00;

Dari data kriteria diatas maka dapat dimasukan kedalam tabel seperti berikut:

Tabel 1. Kriteria

\begin{tabular}{cc}
\hline Kriteria & Keterangan \\
\hline C1 & Jenis Chipset Yang \\
& Digunakan \\
C2 & Ukuran dari RAM/ROM \\
C3 & Ukuran Layar Smartphone \\
C4 & Harga Smartphone \\
\hline
\end{tabular}

Dari masing masing kriteria yang sudah didapat maka akan ditentukan bobotnya dengan menggunakan bilangan Fuzzy yaitu disimbolkan dengan (SR) Sangat Rendah, (R) Rendah, (S) Sedang, (B) Bagus dan (SB) Sangat Bagus. Bilangan bilangan fuzzy yang telah didapat kemudian dikonversikan kedalam bilangan crisp seperti tabel berikut:

Tabel 2. Bobot

\begin{tabular}{cc}
\hline Bilangan Fuzzy & Nilai \\
\hline Sangat Rendah (SR) & 1 \\
Rendah (R) & 2 \\
Sedang (S) & 3 \\
Bagus (B) & 4 \\
Sangat Bagus (SB) & 5 \\
\hline
\end{tabular}


Tabel 3. Kriteria Smartphone

\begin{tabular}{ll}
\hline \multicolumn{1}{c}{ Kriteria } & \multicolumn{1}{c}{ Keterangan } \\
\hline Jenis Chipset Yang Digunakan & Tingkatan dari suatu Chipset yang terbaik \\
Ukuran dari RAM/ROM & Ukuran RAM/ROM dari suatu Smartphone \\
Ukuran Layar Smartphone & Ukuran layar dari Smartphone \\
Harga Smartphone & Harga dari Smartphone \\
\hline
\end{tabular}

\subsubsection{Pembobotan Kriteria Pemilihan Smartphone}

Menghitung nilai dari setiap alternative pada setiap kriteria yang sudah ditentukan.

a. Kriteria Jenis Chipset yang digunakan

Pada kriteria Jenis chipset ditentukan dari tingkatan chipset yang popular dikalangan masyarakat yang dapat dikategorikan dengan bilangan Fuzzy yaitu Bagus (B), Sedang (S), Rendah (R) dan Sangat Rendah (SR) dapat dilihat dalam tabel dibawah ini.

Tabel 4. Kriteria Jenis Chipset

\begin{tabular}{ccc}
\hline Jenis Chipset & Bilangan fuzzy & Bobot \\
\hline Qualcomm Snapdragon & $\mathrm{B}$ & 4 \\
Exynos & $\mathrm{S}$ & 3 \\
Mediatek & $\mathrm{R}$ & 2 \\
Apple & $\mathrm{SR}$ & 1 \\
\hline
\end{tabular}

b. Kriteria Ukuran RAM/ROM

Pada kriteria Ukuran RAM/ROM diprioritaskan semakin tinggi RAM/ROM maka pilihan itu akan semakin diprioritaskan dapat dikategorikan dengan bilangan Fuzzy yaitu Bagus (B), Sedang (S), Rendah (R) dan Sangat Rendah (SR) dapat dilihat pada tabel dibawah ini:

Tabel 5. Kriteria Ukuran RAM/ROM

\begin{tabular}{ccc}
\hline Ukuran RAM/ROM & Bilangan fuzzy & Bobot \\
\hline $2 / 16 \mathrm{~GB}$ & $\mathrm{~B}$ & 4 \\
$4 / 64 \mathrm{~GB}$ & $\mathrm{~S}$ & 3 \\
$6 / 128 \mathrm{~GB}$ & $\mathrm{R}$ & 2 \\
$8 / 128 \mathrm{~GB}$ & $\mathrm{SR}$ & 1 \\
\hline
\end{tabular}

\section{c. Kriteria Ukuran Layar Smartphone}

Pada kriteria ini memiliki berbagai pendapat dari yang mensurvei namun dapat disimpulkan bahwa

Kebanyakan pensurvei memilih Smartphone dengan layar yang besar dapat dikategorikan dengan bilangan Fuzzy Yaitu Sangat Bagus (SB), Bagus (B), Sedang (S), Rendah (R) dan Sangat Rendah (SR) seperti terlihat pada tabel dibawah ini:

Tabel 6. Kriteria Ukuran Layar Smartphone

\begin{tabular}{ccc}
\hline $\begin{array}{c}\text { Ukuran Layar } \\
\text { Smartphone }\end{array}$ & Bilangan fuzzy & Bobot \\
\hline $4,4 "$ & SR & 1 \\
$5,0 "$ & R & 2 \\
$5,5 "$ & S & 3 \\
$5,7 "$ & B & 4 \\
$6,0 "$ & SB & 5 \\
\hline
\end{tabular}

\section{d. Kriteria Harga Smartphone}

Pada kriteria ini lebih diprioritaskan harga yang murah dapat dikategorikan dengan bilangan Fuzzy yaitu Bagus (B), Sedang (S) dan Rendah (R) dapat dilihat pada tabel dibawah ini

Tabel 7. Kriteria Harga Smartphone

\begin{tabular}{ccc}
\hline Ukuran Harga & Bilangan fuzzy & Bobot \\
\hline < Rp. 4.000.000,00; & $\mathrm{B}$ & 2 \\
Rp. 4.000.000,00; - Rp. 6.000.000,00; & $\mathrm{S}$ & 3 \\
> Rp. 6.000.000,00; & $\mathrm{R}$ & 4 \\
\hline
\end{tabular}

Untuk lebih jelas maka setiap alternative perlu diberikan rating kecocokan pada setiap kriteria ditunjukan dengan tabel berikut 
Tabel 8. Kriteria Alternatif

\begin{tabular}{|c|c|c|c|c|}
\hline \multirow[t]{2}{*}{ Alternatif } & \multicolumn{4}{|c|}{ Kriteria } \\
\hline & $\mathrm{C} 1$ & $\mathrm{C} 2$ & $\mathrm{C} 3$ & $\mathrm{C} 4$ \\
\hline Samsung S21 5G & Exynos & $8 / 128 \mathrm{~GB}$ & $6 "$ & Rp 12.999.000,00; \\
\hline Iphone $1164 \mathrm{~GB}$ & Apple & 4/64 GB & $6 "$ & Rp 10.600.000,00; \\
\hline Vivo Y17 & Mediatek & 6/128 GB & $6 "$ & Rp 2.500.000,00; \\
\hline Asus ROG Phone 5 & $\begin{array}{l}\text { Qualcomm } \\
\text { Snapdragon }\end{array}$ & 8/128 GB & $6 "$ & Rp 14.000.000,00; \\
\hline Oppo A92 & $\begin{array}{l}\text { Qualcomm } \\
\text { Snapdragon }\end{array}$ & 8/128 GB & $5,5^{\prime \prime}$ & Rp 3.300.000,00; \\
\hline
\end{tabular}

Kemudian dari tabel diatas ubah menjadi bobot yang telah ditentukan

Tabel 9. Rating Kecocokan

\begin{tabular}{ccccc}
\hline Alternatif & C1 & C2 & Kriteria & C3 \\
\hline Samsung S21 5G & 3 & 4 & 5 & 4 \\
Iphone 11 64 GB & 1 & 2 & 5 & 4 \\
Vivo Y17 & 2 & 3 & 5 & 2 \\
Asus ROG Phone & 4 & 4 & 5 & 4 \\
5 & 4 & 4 & 3 & 2 \\
Oppo A92 & & 4 & 3 \\
\hline
\end{tabular}

Membuat Matriks keputusan untuk mempermudah perhitungan.

$$
R=\left\{\begin{array}{llll}
3 & 4 & 5 & 4 \\
1 & 2 & 5 & 4 \\
2 & 3 & 5 & 2 \\
4 & 4 & 5 & 4 \\
4 & 4 & 3 & 2
\end{array}\right\}
$$

Sebelum melakukan normalisasi terlebih dahulu melakukan Penggolongan Kriteria untuk membedakan attribute keuntungan dan biaya yang akan membantu dalam pemilihan nantinya.

Tabel 10. Rating Kecocokan

\begin{tabular}{ccc}
\hline Kriteria & Benefit & Cost \\
\hline Jenis Chipset Yang Digunakan & 1 & 0 \\
Ukuran dari RAM/ROM & 1 & 0 \\
Ukuran Layar Smartphone & 1 & 0 \\
Harga Smartphone & 0 & 1 \\
\hline
\end{tabular}

a. Untuk menghitung kriteria jenis Chipset yang digunakan dalam atribut keuntungan maka semakin besar nilainya semakin maka akan dianggap semakin baik:
$\mathrm{R} 11=\frac{3}{\operatorname{Max}(3 ; 1 ; 2 ; 4 ; 4)}=0,75$
$\mathrm{R} 12=\frac{1}{\operatorname{Max}(3 ; 1 ; 2 ; 4 ; 4)}=0,25$
$\mathrm{R} 13=\frac{2}{\operatorname{Max}(3 ; 1 ; 2 ; 4 ; 4)}=0,5$
$\mathrm{R} 14=\frac{4}{\operatorname{Max}(3 ; 1 ; 2 ; 4 ; 4)}=1$
$\mathrm{R} 15=\frac{4}{\operatorname{Max}(3 ; 1 ; 2 ; 4 ; 4)}=1$

b. Untuk menghitung kriteria Ukuran RAM/ROM yang digunakan dalam atribut keuntungan maka semakin besar nilainya semakin maka akan dianggap semakin baik:
$\mathrm{R} 21=\frac{4}{\operatorname{Max}(4 ; 2 ; 3 ; 4 ; 4)}=1$
$\mathrm{R} 22=\frac{2}{\operatorname{Max}(4 ; 2 ; 3 ; 4 ; 4)}=0,5$
$\mathrm{R} 23=\frac{3}{\operatorname{Max}(4 ; 2 ; 3 ; 4 ; 4)}=0,75$
$\mathrm{R} 24=\frac{4}{\operatorname{Max}(4 ; 2 ; 3 ; 4 ; 4)}=1$
$\mathrm{R} 25=\frac{4}{\operatorname{Max}(4 ; 2 ; 3 ; 4 ; 4)}=1$

c. Untuk menghitung kriteria Ukuran layar Smartphone yang digunakan dalam atribut keuntungan maka semakin besar nilainya semakin maka akan dianggap semakin baik:
$\mathrm{R} 31=\frac{5}{\operatorname{Max}(5 ; 5 ; 5 ; 5 ; 3)}=1$
$\mathrm{R} 32=\frac{5}{\operatorname{Max}(5 ; 5 ; 5 ; 5 ; 3)}=1$
$\mathrm{R} 33=\frac{5}{\operatorname{Max}(5 ; 5 ; 5 ; 5 ; 3)}=1$ 


$$
\mathrm{R} 34=\frac{5}{\operatorname{Max}(5 ; 5 ; 5 ; 5 ; 3)}=1 \quad \mathrm{R} 35=\frac{3}{\operatorname{Max}(5 ; 5 ; 5 ; 5 ; 3)}=0,6
$$

d. Untuk menghitung kriteria Harga Smartphone yang digunakan dalam atribut keuntungan maka semakin kecil nilainya semakin maka akan dianggap semakin baik:

$$
\begin{array}{ll}
\mathrm{R} 51=\frac{\operatorname{Min}(2 ; 2 ; 4 ; 2 ; 4)}{4}=0,5 & \mathrm{R} 52=\frac{\operatorname{Min}(2 ; 2 ; 4 ; 2 ; 4)}{4}=0,5 \\
\mathrm{R} 53=\frac{\operatorname{Min}(2 ; 2 ; 4 ; 2 ; 4)}{2}=1 & \mathrm{R} 55=\frac{\operatorname{Min}(2 ; 2 ; 4 ; 2 ; 4)}{2}=1 \\
\mathrm{R} 54=\frac{\operatorname{Min}(2 ; 2 ; 4 ; 2 ; 4)}{4}=0,5 &
\end{array}
$$

Maka akan didapat matriks yang tersaji dalam tabel dibawah ini

Tabel 11. Rating Kecocokan

\begin{tabular}{ccccc}
\hline Alternatif & $\mathrm{C} 1$ & $\mathrm{C} 2$ & Kriteria & $\mathrm{C} 4$ \\
\hline Samsung S21 5G & 0,75 & 1 & 1 & 0,5 \\
Iphone 11 64 GB & 0,25 & 0,5 & 1 & 0,5 \\
Vivo Y17 & 0,5 & 0,75 & 1 & 1 \\
Asus ROG Phone & 1 & 1 & 1 & 0,5 \\
5 & 1 & 1 & 0,6 & 1 \\
Oppo A92 & & & & \\
\hline
\end{tabular}

Kemudian lakukan proses perangkingan untuk mengetahui hasil perhitungannya.

$\mathrm{V} 1=0,75(25)+1(25)+1(10)+0,5(40)=18,75+25+10+20=73,75$

$\mathrm{V} 2=0,25(25)+0,5(25)+1(10)+0,5(40)=6,25+12,5+10+20=48,75$

$\mathrm{V} 3=0,5(25)+0,75(25)+1(10)+1(40)=12,5+18,75+10+40=81,25$

$\mathrm{V} 4=1(25)+1(25)+1(10)+0,5(40)=25+25+10+20=80$

$\mathrm{V} 5=1(25)+1(25)+0,6(10)+1(40)=25+25+6+40=96$

Sehingga yang terbesar adalah V5 yaitu Smartphone Oppo A92 sebagai alternative terbaik ditampilkan pada tabel dibawah ini

Tabel 12. Rating Kecocokan

\begin{tabular}{clc}
\hline No & \multicolumn{1}{c}{ Alternatif } & Total nilai \\
\hline 1 & Samsung S21 5G & 73,75 \\
2 & Iphone 11 64 GB & 48,75 \\
3 & Vivo Y17 & 81,25 \\
4 & Asus ROG Phone 5 & 80 \\
5 & Oppo A92 & 96 \\
\hline
\end{tabular}

\subsection{Rancangan Diagram Use Case}

Use case diagram merupakan pemodelan untuk kelakuan (behavior) sistem informasi yang akan dibuat[14]. Sehingga Use Case diagram dapat dikatakan juga gambaran kasar dari suatu sistem.

a. Use Case Admin

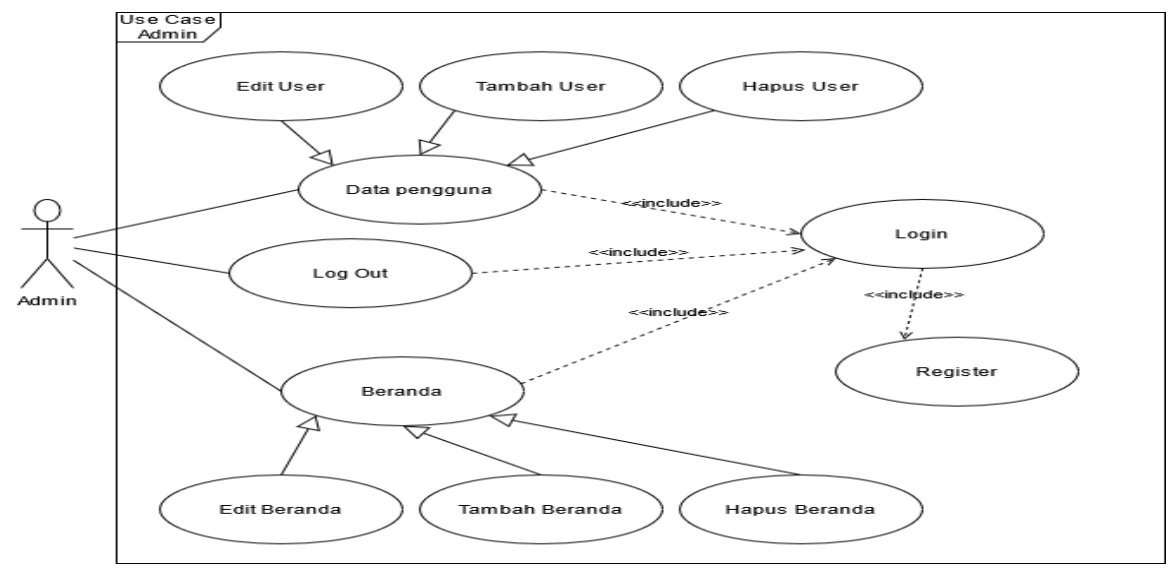

Gambar 1. Use Case Diagram 
Pada Use Case ini admin harus terdaftar dulu pada sistem sehingga data admin ada di dalam sistem. Setelah terdaftar pada sistem admin dapat melakukan login pada sistem. Kemudian admin dapat mengelola data pengguna yang terdaftar pada sistem mulai dari mengubah informasi pengguna jika diperlukan, menambah pengguna baru yang telah mendaftar pada sistem dan menghapus pengguna yang akunnya sudah tidak digunakan. Kemudian admin dapat mengelola tampilan beranda disini admin dapat menambah tentang beberapa teknologi (Smartphone) yang baru saja keluar, mengubah informasi yang salah jika terdapat kesalahan pada informasi yang disediakan, menghapus isi beranda yang sudah tidak perlu lagi misalnya Smartphone tersebut sudah tidak diproduksi lagi atau Smartphone tersebut tidak memiliki izin yang legal sehingga tidak terdapat pelanggaran hokum yang dilakukan. Jika admin sudah tidak punya keperluan pada sistem admin dapat melakukan Log Out atau jika admin sudah selesai mengecek sistem tersebut maka admin dapat Log Out

b. Use Case User

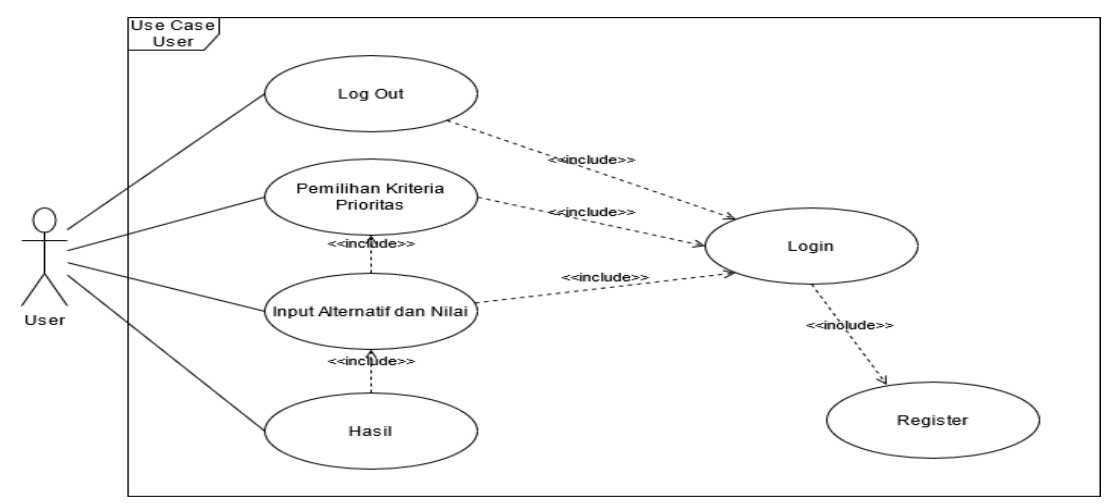

Gambar 2. Use Case User

Disini User (pengguna) dapat masuk kedalam sistem jika sudah melakukan registrasi terlebih dahulu dan jika sudah terverifikasi oleh admin maka User tersebut sudah terdaftar pada sistem. Kemudian baru User bisa Login pada sistem untuk melakukan keperluannya yang terdapat disistem. Jika User sudah Login pada sistem maka dapat menikmati segala fitur yang terdapat pada sistem mulai dari memasukan data Smartphone yang akan dipilih dan dapat memilih prioritas kriteria dari Smartphone yang diinginkan dan jika sudah memasukan semua data makan akan keluar hasil dari perhitungan Smartphone yang sudah terpilih.

\subsection{Implementasi Program}

\section{a. Tampilan Register User}

Pada halaman ini User harus melakukan register atau pendaftaran terlebih dahulu untuk mengakses sistem dimulai dengan mengisikan Username yang akan digunakan dan tentu saja Username nya sesuai dengan kemauan User, kemudian mengisikan Password yang harus diingat oleh User, Ulangi pengisian Password dengan Password yang sama untuk memverifikasi Password tersebut dan mengisikan alamat Email User yang berguna untuk memberikan informasi kepada User jika ada Update dari sistem yang akan dikirim melalui Email dan jika User lupa dengan Password maupun Username dapat mencari tau dengan menuliskan Email User tersebut dan Password dan Username akan dikirimkan melalui Email User.

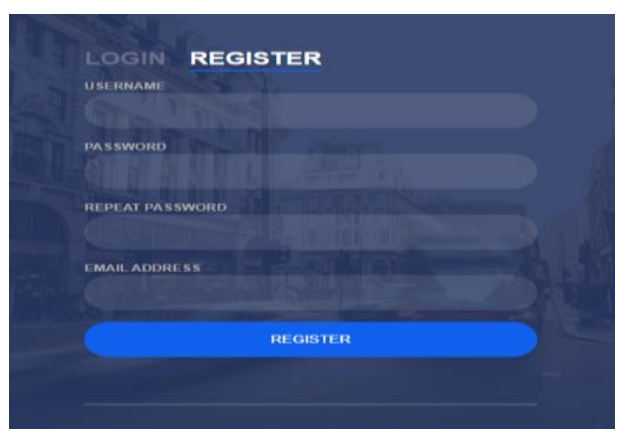

Gambar 3. Tampilan Sistem Register

\section{b. Tampilan Login User}

Pada tampilan ini User dapat Login kedalam sistem dengan memasukan Username yang sudah didaftarkan dan Password yang sudah didaftarkan tadi sehingga User dapat mengakses sistem tersebut. Jika User lupa Passwordnya maka User dapat mengklik Forgot Password dan User akan menerima Email masuk pada Email yang sudah didaftarkan pada proses Registrasi tadi yang mana akan memberitahukan User Password User tersebut sehingga user dapat Login pada halaman tersebut dan mengaksesnya. 


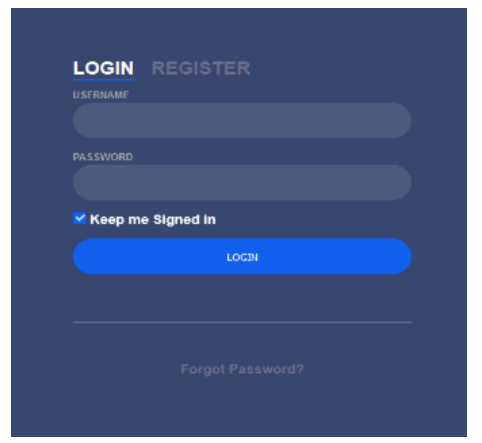

Gambar 4. Tampilan Sistem Login

\section{c. Tampilan Input Smatphone pada User}

Ini adalah menu untuk user mamasukan data Smartphone yang akan dipilihnya kemudian user akan memilih Chipset yang digunakan oleh Smartphone tersebut dan terdapat beberapa pilihan, selanjutnya memasukan berapa ukuran RAM/ROM dari Smartphone tersebut lalu memasukan berapa ukuran layar dari Smartphone tersebut jika sudah langkah berikutnya yaitu memasukan harga dari Smartphone tersebut sesuai dengan harga pasar lalu klik tombol hitung dan akan keluar hasilnya.

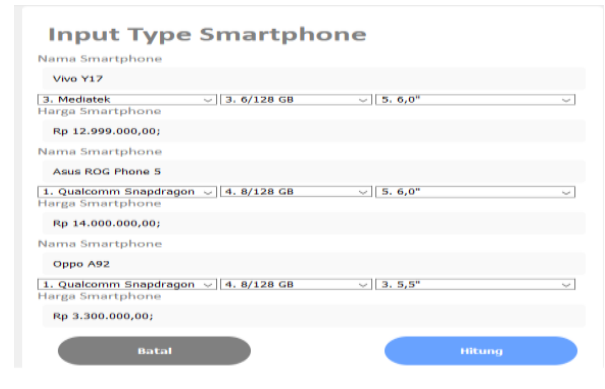

Gambar 5. Tampilan Sistem Input Smartphone

\section{d. Tampilan Input Smatphone pada User}

Pada halaman ini adalah hasil perhitungannya yang mana nilai dari hasil tersebut akan diurutkan dari yang terbesar hingga ke terkecil yang mana pada hasil ini User dapat melihat dan membuat hasil tersebut menjadi patokan dalam memilih Smartphone yang ada dalam list pemilihan keputusannya sehingga User tidak kebingungan dalam melakukan pemilihannya. Jika sudah selesai maka klik tombol selesai untuk keluar dari halaman tersebut sehingga memasuki halaman lain yaitu halaman beranda dan tombol kembali untuk memasukan ulang data dari Smartphone yang akan dipilih jika ada kesalahan.

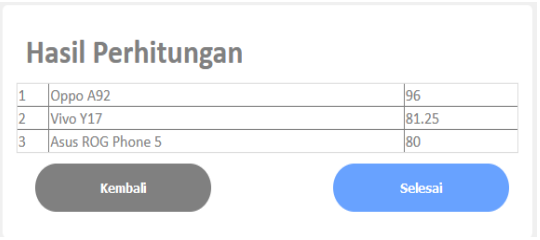

Gambar 6. Tampilan Sistem Hasil

\section{KESIMPULAN}

Dalam pemilihan suatu Smartphone memang terlihat mudah dan gampang namun jika dalam pemilihannya terdapat kesalahan terutama untuk keperluan sehari hari sangatlah sulit apalagi dari banyaknya Spesifikasi dari Smartphone tersebut dan seiiring berjalannya waktu perkembangannya tidak berhenti hanya disitu saja dan pasti akan terus berkembang sehingga kita dipaksa untuk mengikutinya. Selain itu kebutuhan manusia pasti juga akan berbeda tiap individu yang ada sehingga Smartphone yang digunakan juga harus mendukung hal tersebut baik untuk kegiatan sehari hari maupun kegiatan jangka panjang. Tentu saja pemilihan Smartphone untuk jangka panjang menjadi solusi agar dapat mengikuti perkembangan zaman yang kian pesat. Untuk itu pemilihan suatu Smartphone tidak bisa dianggap enteng lagi agar tidak terjadi kesalahan dalam memilih Smartphone untuk kegiatan sehari hari terutama pada spesifikasinya yang begitu beragam. Dengan menggunakan metode Simple Additive Weighting maka dapat dilakukan perhitungan yang terbobot sehingga dapat membandingkan hasilnya dalam kasus ini dapat dilihat bahwa Smartphone yang dipilih adalah Oppo A92 yang mana memiliki keunggulan di Chipset, Ukuran RAM/ROM dan juga harganya yang terjangakau sehingga membuat Smartphone tersebut 
terpilih menjadi alternative yang akan dipilih. Diharapkan dengan ini mahasiswa dapat memilih Smartphone yang sesuai dengan keinginan dan kebutuhannya karena spesifikasi Smartphone yang banyak membuat fungsinya beragam pula ada yang berfokus pada Game hingga tujuan berbelajar sehingga mahasiswa.

\section{REFERENCES}

[1] W. A. G. Natasya, "Sistem Pendukung Keputusan Pemilihan Smartphone Terbaru Menggunakan Metode Analytical Hierarchy Process ( AHP ) TERBARU MENGGUNAKAN METODE ANALYTICAL HIERARCHY SKRIPSI disusun oleh Wirda Astari Galvani Natasya," no. January, 2018.

[2] I. Irfan, A. Aswar, and E. Erviana, "Hubungan Smartphone Dengan Kualitas Tidur Remaja Di Sma Negeri 2 Majene," J. Islam. Nurs., vol. 5, no. 2, p. 95, 2020.

[3] I. J. T. Situmeang, S. Hummairoh, S. M. Harahap, and Mesran, "Application of SAW ( Simple Additive Weighting ) for the Selection of Campus Ambassadors," IJICS (International J. Informatics Comput. Sci., vol. 5, no. 1, pp. 21-28, 2021.

[4] S. K. Simanullang and A. G. Simorangkir, "Sistem Pendukung Keputusan Penerimaan Calon Karyawan Menggunakan Metode Simple Additive Weighting," TIN Terap. Inform. Nusant., vol. 1, no. 9, pp. 472-478, 2021.

[5] W. N. Doni Defriansyah, Islahuddin Daud, "PENGARUH CITRA MEREK, HARGA DAN KUALITAS PRODUK TERHADAP KEPUTUSAN PEMBELIAN SMARTPHONE SAMSUNG (Studi Kasus Mahasiswa Universitas Sriwijaya Indralaya) Doni Defriansyah 1 , Islahuddin Daud 2, \& Welly Nailis 3,” no. 2, pp. 89-102, 2016.

[6] A. Gumelar, "Sistem pendukung keputusan pemilihan handphone dengan metode simple additive weighting (saw) berbasis web," 2017.

[7] C. Septyawan, "Pengaruh Penggunaan Smartphone Terhadap Perilaku Komunikasi Siswa Kelas IX SMPN 3 Sungguminasa," pp. 1-107, 2019.

[8] M. S. S. Pieter and L. T. Ramadhani, "Sistem Pendukung Keputusan Pemilihan Handphone Android Menggunakan Metode Analytical Hierarchy Process," Teknol. Inf., vol. 4, no. 2, pp. 1-13, 2016.

[9] T. Limbong et al., Sistem Pendukung Keputusan: Metode \& Implementasi. Medan: Yayasan Kita Menulis, 2020.

[10] H. Hermanto and N. Izzah, "Sistem Pendukung Keputusan Pemilihan Motor Dengan Metode Simple Additive Weighting (SAW)," Mat. Dan Pembelajaran, vol. 6, no. 2, p. 184, 2018.

[11] R. Y. Simanullang, Melisa, and Mesran, "TIN : Terapan Informatika Nusantara Sistem Pendukung Keputusan Penerima Bantuan Covid-19 Menggunakan Metode Simple Additive Weighting (SAW)," TIN Terap. Inform. Nusant., vol. 1, no. 9, pp. 2-9, 2021.

[12] M. R. Ramadhan, M. K. Nizam, and Mesran, "Penerapan Metode SAW (Simple Additive Weighting) Dalam Pemilihan Siswa-Siswi Berprestasi Pada Sekolah SMK Swasta Mustafa,” TIN Terap. Inform. Nusant., vol. 1, no. 9, pp. 459-471, 2021.

[13] F. Frieyadie, "Penerapan Metode Simple Additive Weight (Saw) Dalam Sistem Pendukung Keputusan Promosi Kenaikan Jabatan," J. Pilar Nusa Mandiri, vol. 12, no. 1, pp. 37-45, 2016

[14] A. Hendini, "Pemodelan Uml Sistem Informasi Monitoring Penjualan Dan Stok Barang," J. Khatulistiwa Inform., vol. 2, no. 9, pp. 107-116, 2016. 